\title{
ANALISIS SENYAWA KIMIA DALAM EKSTRAK KLOROFOM BUNGA KAMBOJA (Plumeria alba) DENGAN GC-MS
}

\author{
Santi Nur Handayani, Kapti Riyani \\ Program Studi Kimia, Jurusan MIPA \\ Fakultas Sains dan Teknik, Universitas Jenderal Soedirman, Purwokerto
}

\begin{abstract}
Plumeria alba is called frangipani is one of Apocynaceae family's plant. Frangipani is potentially used as traditional medicine, for example as an antiinflamation drugs. It has not been yet done an extensive reasearch on the chemical compound content of frangipani. The reasearch was conducted to investigate some chemical constituents by using Gas Chromatography-Mass Spectrometer (GC-MS). Extraction of chemical compound of frangipani has been conducted by soxhletasi using $n$-hexane as solvent followed by chloroform and ethyl acetate. Then chloroform extract was identified by GC-MS. The result showed that extract of chloroform contained : palmitic acid, clionasterol, fucosterol, fagarasterol and methyl commate B respectively.
\end{abstract}

Keywords : chemical compounds, chloroform extract, frangipani

\section{PENDAHULUAN}

yang termasuk ramboja merupakan tanaman Apocynaceae (Heyne, 1987). Tumbuhan ini banyak tumbuh di kuburan, juga ada yang sengaja di tanam di halaman rumah. Kamboja cukup potensial untuk dikembangkan dan dibudidayakan sebagai obat tradisional. Penggunaan genus kamboja baik kulit batang, getah dan daunnya oleh masyarakat sebagai bahan obat tradisional sangat banyak ragamnya dan digunakan secara turuntemurun. Kulit batang kamboja berbunga putih oleh masyarakat sering digunakan sebagai obat patek (frambosia), obat luar untuk kulit pecah-pecah pada telapak kaki, sedangkan air rebusannya dimanfaatkan untuk merendam kaki bengkak. Getah dan daunnya dimanfaatkan untuk mempercepat pecahnya bisul dengan cara dioles sedikit minyak kelapa (Tampubolon, 1995). Bunga kamboja banyak digunakan sebagai campuran farfum, kosmetik dan dapat digunakan sebagai campuran the (kambucha). Penelitian pendahuluan ini dilakukan sebagai awal untuk mengkaji komponen senyawa bioaktif pada bunga kamboja yang berwarna putih.

Penelitian mengenai genus plumeria lain yakni $P$. Rubra dihasilkan senyawa triterpen taraxasteril asetat dan sikloart-22-ena-3 $\square$-25-diol, asam oleanolat dan 13 $\square$-27-dihidroksi-12oleanene, asam 36 $\square$-dihidroksi-3-epioleanenoat (Akhtar, 1992). Senyawasenyawa tersebut aktif terhadap bakteri gram (+) dan bakteri gram (-) diantaranya yaitu Bacillus anthracis, Corynebacterium pseudodiphterium, Pseudomonas aeroginosa dan Pseudomonas pseudomalliae. Penelitian lain terhadap genus ini juga menunjukkan aktivitas inhibitor antitumor hingga 54\% terhadap pertumbuhan tumor. Penelitian Kardono, et. al., (1990) menemukan 7 senyawa dari batang kamboja berbunga merah $P$. rubra memiliki efek sitotoksik terhadap sel kanker murin leukimia (P388) dan sejumlah sel kanker lainnya seperi payudara, kolon, fibrosarkoma, melanoma, KB.

Tanaman ini mengandung fuvoplumierin, yang dapat menghambat pertumbuhan bakteri serta saponin, damar 
dan mengandung senyawa atsiri antara lain: geraniol, farnesol, sitronellol, fenetilalkohol dan linallol (Anonim, 1999). Penelitian ini bertujuan untuk: mengekstraksi dan melakukan penjaringan senyawa kimia yang terdapat dalam bunga kamboja putih dan mengidentifikasi senyawa kimia dalam ekstrak kloroform bunga kamboja dengan GC-MS.

\section{METODE PENELITIAN}

Bahan dan Alat :

Bahan yang digunakan dalam penelitian adalah bunga kamboja putih (Plumeria alba), $n$-heksana, kloroform, etil asetat, plat KLT, $\mathrm{Na}_{2} \mathrm{SO}_{4}$ anhidrat, aquades, bismuth nitrat, asam asetat, kalium iodida, vanilli, $\mathrm{HCl}$ pekat, $\mathrm{NH}_{4} \mathrm{OH}$, dan $\mathrm{KMnO}_{4}$. Alat yang digunakan adalah gelas piala, seperangkat alat ekstraksi Soxhlet, corong, gelas ukur, lampu UV 254 dan 366, neraca analitik, dan evaporator Buchii, Spektrometer GCMS QP2010S Shimadzu.

\section{Prosedur Percobaan}

\section{Ekstraksi soxhletasi (Handayani, 1998)}

Bunga kamboja putih

dikeringkan, kemudian dipotong kecilkecil. Sebanyak $25 \mathrm{~g}$ bunga kamboja disoxhletasi dengan menggunakan $n$ heksana sebanyak $200 \mathrm{~mL}$ selama 7 jam, selanjutnya disaring untuk memperoleh filtrat dan serbuk bebas lemak pelarut. Serbuk diangin-anginkan dan selanjutnya disoxhletasi kembali dengan pelarut kloroform selama 7 jam. Sampel disaring untuk memperoleh filtrat dan filtratnya ditambahkan $\quad \mathrm{Na}_{2} \mathrm{SO}_{4} \quad$ anhidrat secukupnya, lalu disaring, pelarutnya dievaporasi dan serbuknya dianginanginkan. Serbuk disoxhletasi kembali dengan pelarut etil asetat selama 7 jam, selanjutnya disaring dan filtrat hasil penyaringan ditambahkan $\mathrm{Na}_{2} \mathrm{SO}_{4}$ anhidrat secukupnya, lalu disaring dan pelarutnya dievaporasi. Filtrat hasil evaporasi selanjutnya dinamakan ekstrak $n$-heksana, ekstrak kloroform dan ekstrak etil asetat bunga kamboja.

\section{Skrining atau penjaringan senyawa kimia dengan pereaksi warna}

Skrining atau penjaringan adanya senyawa kimia berupa alkaloida, flavonoida, saponin dan senyawa fenol dilakukan dengan plat KLT yang telah ditotoli sampel dan dilakukan penyemprotan dengan :

a. Pereaksi Dragendorff 132 (Cannel, 1998) digunakan untuk uji alkaloid.

b. Pereaksi vanilli-HCl (Markham, 1988) digunakan untuk uji falavanoid terutama katekhin dan antosianidin.

c. Larutan $\mathrm{FeCl}_{3} 5 \%$ (Harborne, 1996), digunakan untuk uji adanya senyawa fenolat.

d. Larutan $\mathrm{KMnO}_{4} 1 \%, \mathrm{HCl} 2 \mathrm{M}$ dan $\mathrm{NH}_{4} \mathrm{OH} 1 \mathrm{M}$ (Uji Maüle) (Harborne, 1987) digunakan untuk uji adanya senyawa flavanoid.

e. Uap ammonia (Geissman, 1962) digunakan utuk uji adanya senyawa flavanoid.

\section{Analisis senyawa kimia ekstrak kloroform bunga kamboja putih dengan GC-MS}

Ekstrak kloroform bunga kamboja putih yang diperoleh dianalisis menggunakan kromatografi gasspektrometer massa, kolom Rtx-5MS panjang kolom $30 \mathrm{~m}$ dan ID 0,25 $\mathrm{m}$.

\section{HASIL DAN PEMBAHASAN}

\section{Ekstraksi Soxhletasi}

Bunga kamboja dipotong kecilkecil dan dijadikan serbuk untuk memperkecil ukuran partikel, sehingga dapat memperluas permukaan dan meningkatkan interaksi antara pelarut dan senyawa yang akan diekstraksi. Isolasi senyawa kimia dari bunga kamboja dilakukan dengan cara sampel diekstraksi selama 7 jam dengan alat ekstraksi soxhlet menggunakan pelarut $n$-heksana, kloroform dan etil asetat secara terpisah. 
Keuntungan dari Soxhletasi ini antara lain sampel yang digunakan dalam jumlah kecil, pelarut yang digunakan tidak terlalu banyak, ekstraksi dapat dilakukan secara berulang-ulang sehingga proses ekstraksi akan lebih efektif. Hasil ekstraksi dengan soxhletasi menggunakan pelarut $n$-heksana, kloroform dan etil asetat secara terpisah disajikan dalam Tabel 1.

Tabel 1. Hasil Soxhletasi bunga kamboja dengan berbagai pelarut

\begin{tabular}{lll}
\hline Jenis & Berat & Warna \\
Pelarut & Ekstrak $(\mathrm{g})$ & Ekstrak \\
\hline$n$-Heksana & 2,514 & $\begin{array}{l}\text { Kuning } \\
\text { kecoklatan }\end{array}$ \\
Kloroform & 3,301 & Hijau \\
Etil asetat & 2,254 & Hijau \\
\hline
\end{tabular}

Pelarut yang digunakan dalam ekstraksi berdasarkan kepolarannya, maka diharapkan dapat diisolasi senyawa-senyawa kimia yang ada dalam bunga kamboja berdasarkan tingkat kepolarannya. Tahap selanjutnya dilakukan uji pendahuluan dengan cara skrining atau penjaringan senyawasenyawa bioaktif dengan menggunakan pereaksi warna.

\section{Skrining atau Penjaringan Senyawa Kimia Pereaksi Warna}

Hasil skrining atau penjaringan dengan menggunakan pereaksi Dragendorff 132 terhadap ekstrak kloroform bunga kamboja, tidak menghasilkan endapan oranye, sehingga ekstrak tersebut mengindikasikan negatif adanya alkaloida dan senyawa yang mengandung senyawa nitrogen (Cannell, 1988). Uji warna menggunakan pereaksi $\mathrm{KMnO}_{4} \quad 1 \%-\mathrm{HCl} 2 \mathrm{M}-\mathrm{NH}_{4} \mathrm{OH} 1 \mathrm{M}$ dan uap ammonia memberikan hasil positif, menunjukkan adanya senyawa flavonoida. Penggunaan pereaksi tersebut masih belum spesifik untuk menentukan golongan dari senyawa flavonoida yang ada.

Uji warna dengan $\mathrm{FeCl}_{3} 5 \%$, menunjukkan adanya senyawa fenolat. Hasil uji skrining atau penjaringan senyawa kimia yang lebih lengkap disajikan dalam Tabel. 2 berikut ini :

Tabel 2. Penjaringan senyawa kimia dari ekstrak bunga kamboja dengan pereaksi warna.

\begin{tabular}{|c|c|c|}
\hline Uji warna & Kloroform & $\begin{array}{l}\text { Senyawa } \\
\text { Bioaktif }\end{array}$ \\
\hline Dragendorf 132 & Hijau & Alkaloid (-) \\
\hline Vanilli-HCl & Hijau & $\begin{array}{l}\text { Kathekhin (-) } \\
\text { antosianidin(-) }\end{array}$ \\
\hline $\mathrm{FeCl}_{3} 5 \%$ & Hijau kecoklatan & Fenolat $(+)$ \\
\hline $\begin{array}{l}\mathrm{KMnO}_{4} 1 \%-\mathrm{HCl} \\
2 \mathrm{M}-\mathrm{NH}_{4} \mathrm{OH} 1 \mathrm{M}\end{array}$ & Coklat & Flavonoid (+) \\
\hline Uap amonia & Hijau & Flavonoid (+) \\
\hline $\mathrm{H}_{2} \mathrm{O}$ dan dikocok & Busa stabil & Saponin $(+)$ \\
\hline
\end{tabular}

\section{Hasil Analisis Ekstrak Kloroform Bunga Kamboja Putih dengan GC-MS} Analisis dengan GC-MS bertujuan untuk mengetahui senyawasenyawa yang terkandung dalam ekstrak kloroform bunga kamboja. Hal ini dilakukan dengan tujuan untuk mengetahui senyawa-senyawa bioaktif yang larut dalam pelarut semi polar.

Data yang diperoleh berupa persen kelimpahan relatif, ion molekuler dan pola fragmentasi dari senyawa- 
senyawa yang spesifik. Analisis GC-MS terhadap ekstrak hasil isolasi bunga kamboja dengan pelarut kloroform menghasilkan 69 puncak, namun dalam analisis pola fragmentasi dipilih 6 puncak yang memiliki \% area terbesar. Hasil kromatogram dari senyawa hasil isolasi bunga kamboja dengan pelarut kloroform dapat dilihat pada Gambar 1. Waktu retensi dan \% area masing-masing puncak dari kromatogram GC-MS dilihat pada Tabel 3.

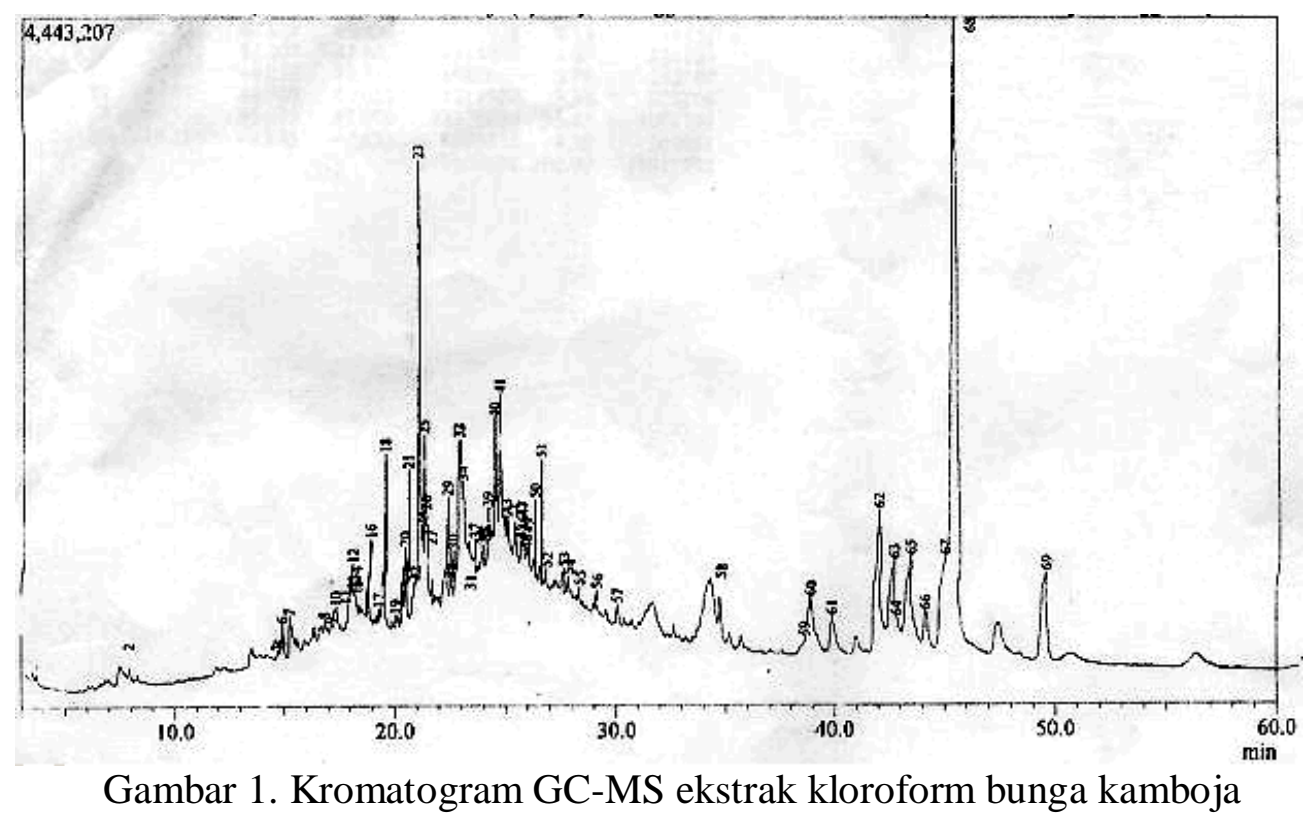

Fragmentasi puncak-puncak kromatogram ekstrak kloroform bunga berdasarkan SI (persen kemiripan, ion molekuler (BM), karakter spektra massa dan limpahan relatif ion $(\mathrm{m} / \mathrm{z})$ dan senyawa-senyawa yang diperkirakan dapat ditampilkan pada Lampiran 1 . Berdasarkan spektra massa dari tiap puncak yang telah difragmentasi dengan mengacu pada literatur Budzikiewicz, et.al .,1967, Kitson, et.al.,1996, dan Silverstein, et.al.,1991, dan dibandingkan spektra standar dari literatur komputer (library), 6 puncak diantaranya telah berhasil diidentifikasi.

Tabel 3. Data waktu retensi dan $\%$ area dari 6 puncak dengan $\%$ kelimpahan relatif yang terbesar dari data kromatogram GC-MS

\begin{tabular}{ccc}
\hline Puncak ke- & $\begin{array}{c}\text { Waktu retensi } \\
\text { (menit) }\end{array}$ & $\%$ area \\
\hline 23 & 20,975 & 5,48 \\
62 & 41,950 & 5,46 \\
63 & 42,633 & 2,43 \\
65 & 43,367 & 2,20 \\
68 & 45,350 & 33,45 \\
69 & 49,517 & 4,06 \\
\hline
\end{tabular}

Dari 69 puncak yang dihasilkan dari GC-MS tersebut (Lampiran 1), 6 puncak merupakan komponen utama seperti terlihat dalam Gambar 2: 


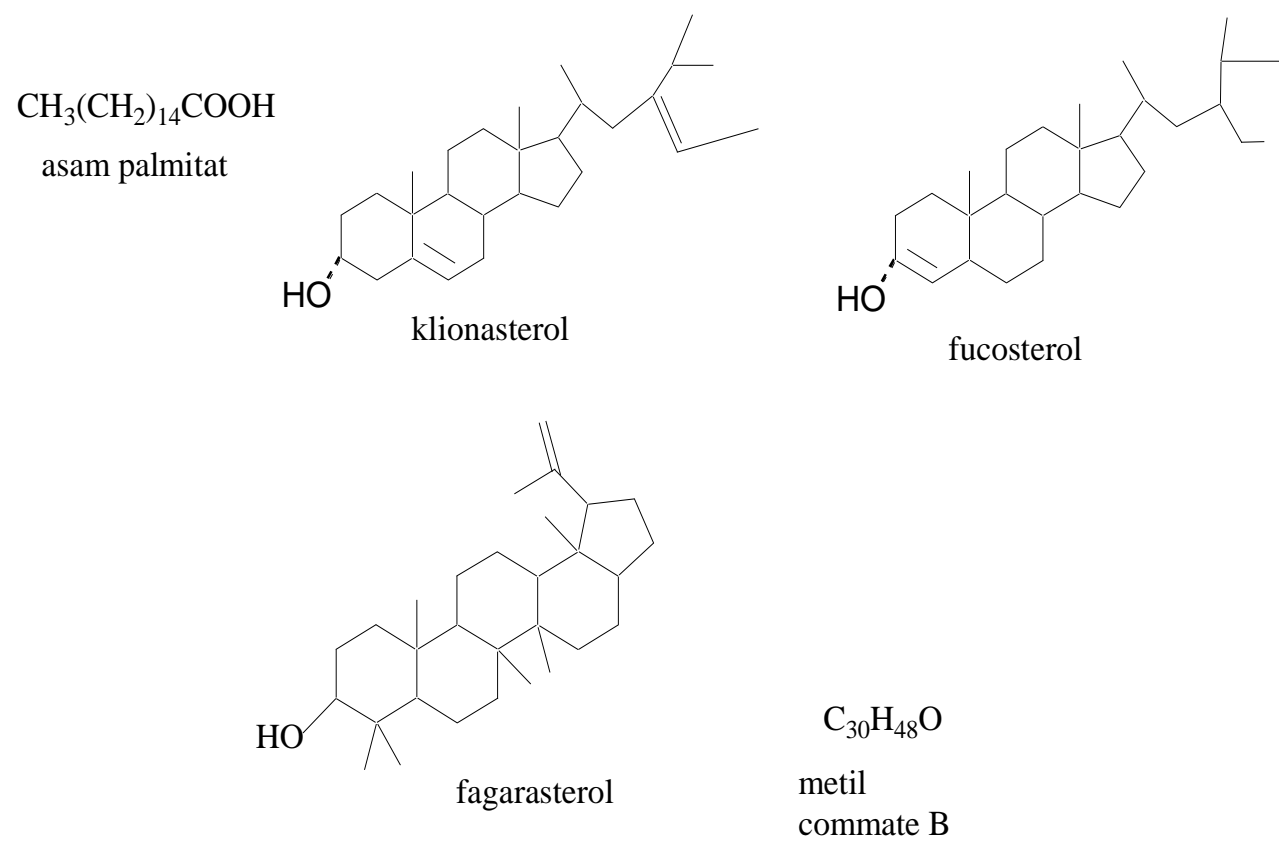

Gambar 2. Komponen utama ekstrak kloroform bunga kamboja

\section{KESIMPULAN}

Berdasarkan hasil penelitian yang telah dilakukan dapat disimpulkan bahwa :

1. Hasil uji skrining atau penjaringan senyawa bioaktif dari ekstrak kloroform bunga kamboja menggunakan pereaksi warna mengindikasikan positif adanya senyawa fenolat, senyawa flavonoid, dan saponin.

2. Hasil identifikasi senyawa hasil ekstrak etil asetat batang combrang menggunakan GC-MS yang diperoleh 69 puncak. Namur hanya 6 puncak dengan luas areanya terbesar diantaranya puncak 23 diduga merupakan senyawa asam palmitat, puncak 62 merupakan senyawa klionasterol, puncak 63 diduga merupakan senyawa fukosterol, puncak 65 dan 68 merupakan senyawa fagarasterol dan puncak 69 diduga merupakan puncak metil commate B.

\section{DAFTAR PUSTAKA}

Aktar, N. 1992. Isolation and Structural Studies on the Constituents of Calotropis Procera, Plumeria and Amberboa Ramose. Thesis. H.E.J. Researc Institute of Chemistry University of Karachi. Pakistan Research Repository.

Anonim, 1999. Tanaman Obat Keluarga. Jakarta : PT. Intisari Mediatama.

Budzikiewicz, H., Djerassi, C., dan William, D.H. 1967. Mass Spectrometry of Organic Compound. Holden-Day Inc. San Fransisco.

Cannell, R.J.R. 1998. Natural Product Isolation. Human Press New Jersey.

Geissman. 1962. The Chemistry of Flavonoid Compounds. The Mac Millan Company. New York.

Handayani, S.N., 1998. Isolasi dan Identifikasi Arekolin dan 
Isoflavon dalam Biji Pinang (Areca catechu L). Skripsi. Jurusan Kimia. FMIPA. UGM. Yogya.

Harborne, J.B. 1996. Metode Fitokimia Penuntun Cara Menganalisis Tumbuhan. Terbitan Kedua. ITB Bandung.

Heyne, K. 1987. Tumbuh-Tumbuhan Berguna di Indonesia. Terjemahan. Yayasan Sarana Warna. Jakarta. 565-567.

Kardono, L.B., Tsauri, S., Padmawinata, K., Pezzuto, J.M, and Kinghorn, A.D., $1990 . \quad$ Cytotoxic Constituents of The Bark of Plumeria rubra Collected in Indonesia. J. Nat. Product. NovDec. 53 (6): 1447-1455.

Kitson, F.G.Larsen, B.S dan M.C. C.N, 1996. Gas Chromatography and Mass Spectrometry a Practical
Guide. Academic Press. San Diego.

Markham, K.R. 1988. Cara Mengidentifikasi Flavonoid. Penerbit ITB. Bandung.

Sastrohamidjojo, H,. 1988. Interpretasi Spektra Massa. GMU Press. Yogyakarta (Terjemahan dari Mc. Lafferty. 1980. Interpretation of Mass Spectra. Third Edition. University Science Book).

Silverstein, R.M., Bassler, G.C, and Morril, T.C.. 1991. Spectrometric Identification of Organic Compounds. Fifth edition. John Wiley and Sons Inc. New York.

Tampubolon, O. T. 1995. Tumbuhan Obat. Jakarta : Penerbit Bhratara. 
Analisis Senyawa Kimia dalam ...(Santi Nur Handayani dan Kapti R)

Lampiran 1. Fragmentasi dan identifikasi puncak kromatogram ekstrak kloroform bunga kamboja

\begin{tabular}{|c|c|c|c|c|c|}
\hline No.Puncak & SI & $\mathrm{BM}$ & $\begin{array}{l}\text { Karakter Spektra Massa } \\
\text { Limpahan Relatif Ion, m/2 }\end{array}$ & $\begin{array}{l}\text { a dan } \\
/ \mathrm{z}^{+}(\%)\end{array}$ & $\begin{array}{c}\text { Senyawa } \\
\text { yang diperkirakan }\end{array}$ \\
\hline 1 & 94 & 256 & $\begin{array}{l}41(58,82), 43(100), 60(72,06), \\
85(27,94), \quad 98(17,65), \quad 1 \\
129(30,88), \quad 143(5,88), \quad 157(11 \\
(8,82), 185(10,29), 199(4,41), 2 \\
227(5,88), 256(13,24)\end{array}$ & $\begin{array}{l}73(91,18), \\
115(14,71) \\
1,76), 171 \\
213(13,24),\end{array}$ & Asam palmitat \\
\hline 2 & 95 & 414 & $\begin{array}{lcc}43(1,7), & 57(47), \quad 81(52,94), \\
119(47), & 133(23,53), & 1 \\
159(23,53), & 185(11,76), & \\
213(26,47), & 231(11,76), & 2 \\
273(11,76), & 303(17,65), & 3 \\
396(14,7), 414(23,53) & \end{array}$ & $\begin{array}{r}95(24,2), \\
145(30,59), \\
199(8,82), \\
255(14,71), \\
329(23,53),\end{array}$ & Klionasterol \\
\hline 3 & 90 & 412 & $\begin{array}{lcc}41(48,53), & 55(100), 69(52,94), \\
95(35,29), & 105(29,41), & 1 \\
133(20,59), & 145(23,53), & 1 \\
173(11,76), & 187(5,88), & \\
211(22,06), & 229(38,24), & \\
253(7,06), & 271(8,82), & \\
299(26,47), 314(85,31) & \end{array}$ & $\begin{array}{r}81(47,06), \\
119(24,41), \\
159(17,65), \\
199(7,35), \\
239(5,88), \\
281(0,41),\end{array}$ & Fucosterol \\
\hline 4 & 95 & 426 & $\begin{array}{lcc}41(27,94), & 55(29,41), & \\
81(29,41), & 95(32,35), & 1 \\
135(20,59), & 147(11,76), & \\
175(11,76), & 189(20,59), & 2 \\
218(100), & 229(1,18), & \\
257(2,94), & 272(1,47), & \\
411(8,82), 426(5,88) & & \end{array}$ & $\begin{array}{r}69(41,18), \\
109(23,53), \\
161(8,82), \\
203(52,94), \\
243(1,47), \\
393(2,94),\end{array}$ & Fagarasterol \\
\hline 5 & 90 & 426 & $\begin{array}{llr}41(47,06), & 43(62,94), & \\
69(52,94), & 81(67,65), & \\
109(58,82), & 121(52,94), & 1 \\
147(29,41), & 161(26,47), & 1 \\
189(55,88), & 207(47,06), 218( \\
(8,82), 247(2,94), 272(2,94), \\
315(5,88), & 370(1,176), & 3 \\
411(5,98), 426(11,76)\end{array}$ & $\begin{array}{r}55(51,47), \\
95(73,53), \\
135(61,76), \\
175(22,06), \\
(100), 229 \\
299(1,47), \\
383(1,176),\end{array}$ & Fagarasterol \\
\hline 7 & 90 & 468 & $\begin{array}{lcr}41(41,18), & 43(1), 55(70,59), \\
81(60,29), & 95(72,06), & 1 \\
121(58,82), & 135(52,94), \quad 1 \\
161(23,53), & 175(17,65), \quad 189 \\
203(64,71), & 218(79,41), \\
249(8,82), & 272(2,94), \\
331(1,18), & 342(1,18), & \\
393(4,41), & 408(2,94), \\
426(1,18), 453(4,41), 468(10,29\end{array}$ & $\begin{array}{r}69(61,76), \\
107(69,12), \\
147(29,41), \\
9 \quad(58,82), \\
229(5,88), \\
289(1,18), \\
357(2,94), \\
426(1,18), \\
9)\end{array}$ & Metil commate B \\
\hline
\end{tabular}

